\title{
Article \\ Phase-Controlled NiO Nanoparticles on Reduced Graphene Oxide as Electrocatalysts for Overall Water Splitting
}

\author{
Seung Geun Jo ${ }^{1}$, Chung-Soo Kim ${ }^{2, *}$, Sang Jun Kim ${ }^{1,3, * \mathbb{C}}$ and Jung Woo Lee ${ }^{1, *(1)}$ \\ 1 Department of Materials Science and Engineering, Pusan National University, Busan 46241, Korea; \\ linkroot1128@pusan.ac.kr \\ 2 Analysis \& Certification Center, Korea Institute of Ceramic Engineering \& Technology, Jinju 52851, Korea \\ 3 Institute of Materials Technology, Pusan National University, Busan 46241, Korea \\ * Correspondence: cskim@kicet.re.kr (C.-S.K.); ksj0125@pusan.ac.kr (S.J.K.); jungwoolee@pusan.ac.kr (J.W.L.); \\ Tel.: +82-51-510-2898 (J.W.L.)
}

\begin{abstract}
Efficient water electrolysis is one of the key issues in realizing a clean and renewable energy society based on hydrogen fuel. However, several obstacles remain to be solved for electrochemical water splitting catalysts, which are the high cost of noble metals and the high overpotential of alternative catalysts. Herein, we suggest Ni-based alternative catalysts that have comparable performances with precious metal-based catalysts and could be applied to both cathode and anode by precise phase control of the pristine catalyst. A facile microwave-assisted procedure was used for $\mathrm{NiO}$ nanoparticles anchored on reduced graphene oxide ( $\mathrm{NiO} \mathrm{NPs} / \mathrm{rGO}$ ) with uniform size distribution in $\sim 1.8 \mathrm{~nm}$. Subsequently, the Ni-NiO dual phase of the NPs (A-NiO NPs/rGO) could be obtained via tailored partial reduction of the NiO NPs/rGO. Moreover, we demonstrate from systematic HADDF-EDS and XPS analyses that metallic Ni could be formed in a local area of the $\mathrm{NiO} \mathrm{NP}$ after the reductive annealing procedure. Indeed, the synergistic catalytic performance of the $\mathrm{Ni}-\mathrm{NiO}$ phase of the A-NiO NPs/rGO promoted hydrogen evolution reaction activity with an overpotential as $201 \mathrm{mV}$ at $10 \mathrm{~mA} \mathrm{~cm}^{-2}$, whereas the NiO NPs/rGO showed $353 \mathrm{mV}$. Meanwhile, the $\mathrm{NiO} \mathrm{NPs} / \mathrm{rGO}$ exhibited the most excellent oxygen evolution reaction performance among all of the Ni-based catalysts, with an overpotential of $369 \mathrm{mV}$ at $10 \mathrm{~mA} \mathrm{~cm}^{-2}$, indicating that they could be selectively utilized in the overall water splitting. Furthermore, both catalysts retained their activities over $12 \mathrm{~h}$ with constant voltage and 1000 cycles under cyclic redox reaction, proving their high durability. Finally, the full cell capability for the overall water electrolysis system was confirmed by observing the generation of hydrogen and oxygen on the surface of the cathode and anode.
\end{abstract}

Academic Editor: Yuichi Negishi

Received: 17 November 2021

Accepted: 7 December 2021

Published: 13 December 2021

Publisher's Note: MDPI stays neutral with regard to jurisdictional claims in published maps and institutional affiliations.

Keywords: dual phase-controlled catalyst; $\mathrm{Ni}-\mathrm{NiO}$ nanoparticle; overall water splitting; hybrid electrocatalyst; renewable energy

\section{Introduction}

Hydrogen fuel is one of the promising alternative energy resources to replace fossil fuels, because of its intrinsic gravimetric energy density $\left(142 \mathrm{MJ} \mathrm{kg}^{-1}\right)$ and zero-emission nature $[1,2]$. Among various types of hydrogen generation procedures, such as steam reforming, partial oxidation of hydrocarbons, coal gasification, and by-product hydrogen generation from industrial processes [3-7], the electrochemical water splitting is the most favorable method as a clean and facile way in that it only produces hydrogen and oxygen from water molecules under external electric bias [8]. However, it still also demands a large amount of energy to generate hydrogen from water due to its high overpotential from the activation energy barrier of the electrode, the resistance of the electrolyte, and contact resistance at the electrode interface [7]. To this end, it is necessary for electrocatalysts to overcome the limitations that would enable the reduction in applied electric potential for enhanced efficiency of water splitting. 
Generally, Pt-based electrocatalysts are used for hydrogen evolution reaction (HER) and $\mathrm{Ru}$ - or Ir-based materials are applied to oxygen evolution reaction (OER) because of their excellent catalytic activities [9-11]. However, they are noble metals, which are very expensive and deficient in the Earth's crust, thereby hindering commercialized use. Hence, it is imperative to find out Earth-abundant, cost-effective, and highly catalytically active materials such as transition metal-based catalysts [12,13].

Along this direction, many studies have been conducted on electrochemical water splitting using transition metals, which show considerable catalytic activity according to the volcano curve. Among them, $\mathrm{Ni}$ is the most promising candidate due to its high electronic conductivity, thermal stability, and alkaline corrosion resistance [14,15]. Moreover, its phase could be tuned by combining with other metals [16-18] or non-metals such as nickel sulfide [19,20], nickel selenide [21], and nickel phosphide [22,23] to enhance catalytic performance. In addition, it was reported that the dual-phase of $\mathrm{Ni}-\mathrm{NiO}$ nanostructures could show synergistic effects in HER [24,25], and also NiO could show suitable activity and durability in OER [9].

On the other hand, graphene is an attractive supporting material of the electrocatalyst to provide a high theoretical specific surface area $\left(2630 \mathrm{~m}^{2} \mathrm{~g}^{-1}\right)$ [26] and intrinsic electron mobility $\left(200,000 \mathrm{~cm}^{2} \mathrm{~V}^{-1} \mathrm{~s}^{-1}\right)$ [27]. Moreover, reduced graphene oxide (rGO) is one of the graphene materials synthesized by chemically exfoliated procedure, which could be mass productive, preserving the advantages of the graphene. Therefore, rGO is suitable for practical use as supporting material $[28,29]$.

Herein, we report on $\mathrm{NiO}$ nanoparticles (NPs) anchored on rGO by facile microwaveassisted synthesis and the control of their interface via reductive annealing. The NPs were anchored on the rGO surface in a uniform size, and they showed high catalytic activity, preventing aggregation during a chemical reaction. Additionally, a partial reduction step processed by post-annealing resulted in co-existing phases of nickel and nickel oxide. We found that annealed NiO NPs showed superior performance in HER, while as-synthesized NPs represented higher activity in OER than other catalysts. This suggests that each catalyst could be adopted selectively in both electrodes. In addition, they had excellent durability in alkaline media, maintaining the redox reaction capability for 1000 cycles at a constant potential over $12 \mathrm{~h}$. Finally, these materials were applied to the overall water electrolysis system and confirmed their availability by the generation of hydrogen and oxygen on the individual electrode surfaces.

\section{Materials and Methods}

\subsection{Synthesis of $\mathrm{NiO} N P \mathrm{~s} / \mathrm{rGO}$}

Nickel oxide nanoparticles / reduced graphene oxide (NiO NPs/rGO) was synthesized using a microwave-assisted method. First, $10 \mathrm{mg}$ of rGO (Angstron Materials, Dayton, $\mathrm{OH}, \mathrm{USA}$ ) and $50 \mathrm{~mL}$ of diethylene glycol (DEG, Junsei, Tokyo, Japan, 99\%) were mixed in a $50 \mathrm{~mL}$ glass vial with ultrasonication for $3 \mathrm{~h}$. Subsequently, $1 \mathrm{~mL}$ of $50 \mathrm{mM}$ nickel (II) chloride hexahydrate $\left(\mathrm{NiCl}_{2} \cdot 6 \mathrm{H}_{2} \mathrm{O}\right.$, Junsei, $97 \%$ ) and $1 \mathrm{~mL}$ of $0.5 \mathrm{M}$ sodium hydroxide ( $\mathrm{NaOH}$, Junsei, 97\%) were added into the solution, followed by sonication for $1 \mathrm{~h}$. The solution was transferred to a $250 \mathrm{~mL}$ round flask and heated in a microwave oven with $700 \mathrm{~W}$ for $2 \mathrm{~min}$. After cooling to room temperature, the solution was transferred to a $50 \mathrm{~mL}$ conical tube and centrifuged at $8000 \mathrm{rpm}$ for $50 \mathrm{~min}$. Then, the supernatant liquid was decanted, and the residual catalyst was washed with acetone (Daejung, Siheung, Korea, 99.9\%) several times. Finally, the samples were dried in a vacuum oven at $60{ }^{\circ} \mathrm{C}$ overnight. As a control sample, nickel oxide nanoparticles/graphene oxide (NiO NPs/GO) were also synthesized by the same process.

\subsection{Synthesis of $A-N i O N P s / r G O$}

Annealed nickel oxide nanoparticles/reduced graphene oxide (A-NiO NPs/rGO) was fabricated by an additional thermal process. The $\mathrm{NiO} \mathrm{NPs} / \mathrm{rGO}$ was placed in a quartz tube furnace and annealed at $400{ }^{\circ} \mathrm{C}$ for $3 \mathrm{~h}$ under $\mathrm{Ar} / \mathrm{H}_{2}$ atmosphere with a flow rate 
of $100 \mathrm{sccm} / 80 \mathrm{sccm}$. For comparison, the $\mathrm{NiO} \mathrm{NPs} / \mathrm{rGO}$ was heated at $300{ }^{\circ} \mathrm{C}(\mathrm{A}-\mathrm{NiO}$ $\left.\mathrm{NPs} / \mathrm{rGO}\left(300^{\circ} \mathrm{C}\right)\right)$ and $500{ }^{\circ} \mathrm{C}\left(\mathrm{A}-\mathrm{NiO} \mathrm{NPs} / \mathrm{rGO}\left(500^{\circ} \mathrm{C}\right)\right)$ to investigate the effect of the annealing temperature. It was heated only with $\mathrm{Ar}$ atmosphere at the same temperature $\left(400{ }^{\circ} \mathrm{C}\right)$ and flow rate $(100 \mathrm{sccm})$ to investigate the effect of the annealing atmosphere. In addition, the $\mathrm{NiO} \mathrm{NPs} / \mathrm{GO}$ was annealed under the same conditions, producing A-NiO NPs/GO.

\subsection{Materials Characterization}

The surface morphologies and elemental compositions were investigated by field emission transmission electron microscopy (FE-TEM, Talos F200X, Thermo Fisher Scientific, Waltham, MA, USA) and an aberration-corrected TEM (Cs-corrected TEM, Themis Z, FEI company, Hillsboro, OR, USA) equipped with energy dispersive spectroscopy (EDS, Super $X, F E I$ company). The chemical states and bonding structures were analyzed using an X-ray photoelectron spectrometer (XPS, K-Alpha, Thermo Fisher Scientific) with a monochromated $\mathrm{Al} \mathrm{K} \alpha(1486.6 \mathrm{eV})$. Inductively coupled plasma optical emission spectrometry (ICP-OES, Optima 8300, Perkin Elmer, Waltham, MA, USA) was used to characterize the amount of $\mathrm{Ni}$ from the catalysts.

\subsection{Electrochemical Measurement}

All electrochemical performances were evaluated by using a standard three-electrode cell system connected to an electrochemical workstation (VSP, Biologic, Grenoble, France) with a rotating ring-disk electrode rotator (RRDE-3A, ALS, Tokyo, Japan). All used electrodes and voltammetry cells were made of polymer (polyether ether ketone, polymethyl pentene) to exclude the effect of glass dissolution by alkaline electrolytes during the reaction [30,31]. Pt wire (EC Frontier, Kyoto, Japan) and $\mathrm{Hg} / \mathrm{HgO}(20 \% \mathrm{KOH}$ filled) were used as a counter and a reference electrode, respectively. In addition, $1 \mathrm{M} \mathrm{KOH}$ solution (Junsei, Tokyo, Japan, 85\%) was used as an electrolyte. To produce a homogeneous ink, $4 \mathrm{mg}$ of catalyst, $1 \mathrm{~mL}$ of ethanol (OCI company, Seoul, Korea, 99.9\%), and $80 \mu \mathrm{L}$ of Nafion solution (5 wt \%, Alfa Aesar, Haverhill, MA, USA) were mixed by ultrasonication for $30 \mathrm{~min}$. Then, $15 \mu \mathrm{L}$ of the catalyst ink was drop-casted and dried on a glassy carbon electrode (GCE, $5 \mathrm{~mm}$ diameter, ALS, Tokyo, Japan) with $\sim 0.28 \mathrm{mg} \mathrm{cm}^{-2}$ loading amount. Both HER and OER catalytic activities were analyzed by linear sweep voltammetry (LSV) at a scan rate of $5 \mathrm{mV} \mathrm{s}^{-1}$ with a potential range of $-0.70-0.10 \mathrm{~V}$ vs. reversible hydrogen electrode (RHE) for HER and 1.10-1.90 V vs. RHE for OER. Tafel slopes were obtained from the corresponding LSV curves. The charge transfer resistance of the catalysts was measured using electrochemical impedance spectroscopy (EIS) in the frequency range from $100 \mathrm{kHz}-0.01 \mathrm{~Hz}$. Moreover, turnover frequency (TOF) was calculated to compare the hydrogen turnover rate of each catalyst and detailed calculation was shown in the electronic supplementary information (ESI). The catalytic durability was evaluated from the cyclic voltammetry (CV) measurement at a scan rate of $50 \mathrm{mV} \mathrm{s}^{-1}$ for 1000 cycles, and also the chronoamperometry (CA) under a given potential of $-0.30 \mathrm{~V}$ vs. RHE (HER) and $1.53 \mathrm{~V}$ vs. RHE (OER) for $12 \mathrm{~h}$. The measured potentials were calibrated with a reversible hydrogen electrode (RHE) using the following equation:

$$
\mathrm{E}_{\mathrm{RHE}}=\mathrm{E}_{\mathrm{Hg} / \mathrm{HgO}}+0.0591 \mathrm{pH}+0.098
$$

The electrochemical performances of all catalysts, including commercial $20 \mathrm{wt} \% \mathrm{Pt} / \mathrm{C}$ (Alfa Aesar) and 20 wt \% Ir/C (Fuel Cell Store, College Station, TX, USA), were evaluated under the same conditions. The overall water splitting experiment was conducted in a two-electrode cell system. Here, $\mathrm{Ni}$ foams $(1.5 \mathrm{~cm} \times 1.5 \mathrm{~cm})$ were used as current collectors of the working and the counter electrodes. For the general preparation of current collectors, they were washed with ethanol and then immersed in $3 \mathrm{M} \mathrm{HCl}$ for $20 \mathrm{~min}$ to remove the $\mathrm{NiO}$ surface, followed by additional rinsing with the ethanol. As the next step, the pre-treated $\mathrm{Ni}$ foams were dip-coated with $\sim 2.0 \mathrm{mg} \mathrm{cm}^{-2}$ loading amount of the catalyst ink and dried overnight in a vacuum oven at $60^{\circ} \mathrm{C}$. The catalytic activity was measured by 
LSV at a scan rate of $5 \mathrm{mV} \mathrm{s}^{-1}$ and a potential range of 0.50 to $2.50 \mathrm{~V}$. Finally, the long-term stability of the catalysts was estimated at a potential of $2.00 \mathrm{~V}$ for $12 \mathrm{~h}$.

\section{Results and Discussion}

\subsection{Morphology and Structure Characterizations of A-NiO NPs/rGO}

Figure 1 shows a schematic illustration of the overall water splitting in an alkaline electrolyte with two reactions generated at individual electrodes. At the cathode side, HER occurs, wherein a water molecule is dissociated into a hydrogen ion and a hydroxide ion, and then the hydrogen ion adsorbs on the catalyst surface. After that, the adsorbed hydrogen reacts with another water molecule or another neighboring hydrogen intermediate, generating a hydrogen molecule [32]. In alkaline media, there are only trace amounts of hydrogen ions, which could participate in HER, so that water molecules should be dissociated. For this reason, HER electrocatalysts are required to be active in the dissociation of water molecules and also have moderate energy to attach and detach hydrogen easily on their surface. In addition, at the anode side, the OER takes place, wherein a hydroxide ion adsorbs on the catalyst surface, and then another hydroxide ion participates in the reaction, thereby finally generating an oxygen molecule [33]. In the case of the OER, a hydroxide ion mainly involves in the reaction. Thus, it is necessary for the OER catalyst to interact with negatively charged hydroxide ions.

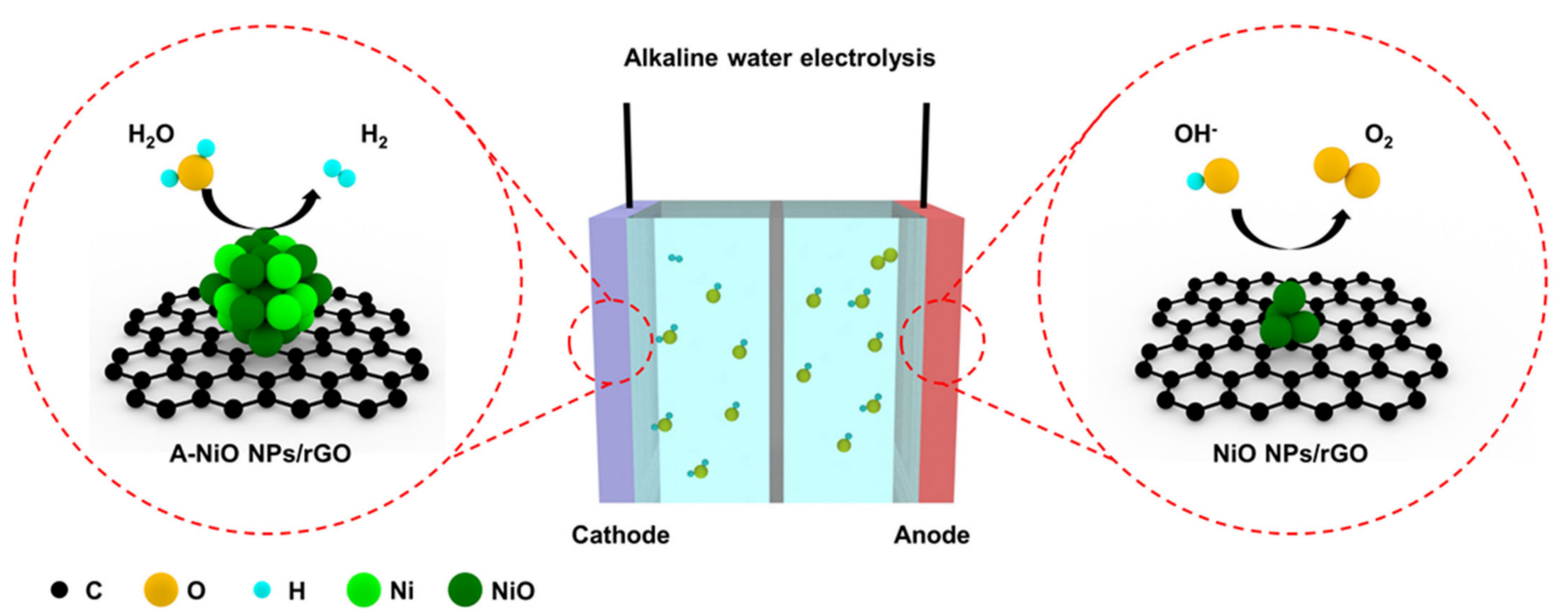

Figure 1. Schematic illustration of the alkaline water electrolysis, where A-NiO NPs/rGO is used for $\mathrm{HER}$ and $\mathrm{NiO}$ NPs/rGO is applied to OER. Colored spheres indicate several elements (Black: C, Yellow: O, Cyan: H, Light green: Ni, Dark green: $\mathrm{NiO})$.

Several studies have tried to enhance the catalytic activity of both HER and OER by metal-carbon coupling, heteroatom doping, or the introduction of additional metals. However, they had significant drawbacks such as high temperature-involved or time-consuming synthesis, catalyst aggregation, and relatively large-size particles. Herein, we fabricated a few nanometer-sized $\mathrm{NiO}$ particles on the rGO by facile and fast microwave-assisted synthesis and controlled their interface by mild thermal annealing process under reductive atmosphere. Based on previous reports, the co-existence of metallic and oxide phases with $\mathrm{Ni}$ and $\mathrm{NiO}$ could show synergistic effects in HER for water molecule dissociation and hydrogen generation $[24,25]$. Moreover, single $\mathrm{NiO}$ would be efficient in OER for hydroxide ion adsorption [9]. From this point of view, we selectively adopted phase-controlled electrocatalysts into the cathode and the anode for overall water splitting. After preparation of the $\mathrm{NiO} \mathrm{NPs} / \mathrm{rGO}$, the morphology and structure of the electrocatalysts were investigated by TEM.

As shown in Figure 2a, the particles on the synthesized NiO NPs/rGO were clearly observed in high magnification and they were uniformly dispersed on the surface of the 
rGO in a round shape without any agglomeration. Based on high-resolution TEM images, the size of NPs was determined to be $1.8 \mathrm{~nm}$ on average (see Figure $2 \mathrm{~b}$ ). Figure S1a,c and Figure $2 \mathrm{c}$ demonstrate the annealed $\mathrm{NiO} \mathrm{NPs} / \mathrm{rGO}$ in a reductive atmosphere at $300{ }^{\circ} \mathrm{C}$, $400{ }^{\circ} \mathrm{C}$, and $500{ }^{\circ} \mathrm{C}$, respectively. As the annealing temperature elevated, the sizes of the NPs increased to 4.4,5.7, and $9.7 \mathrm{~nm}$, because smaller NPs preferred to dissolve and attach to neighboring larger particles by Ostwald ripening (see Figure S1b,d and Figure 2d) [34]. Additionally, the NPs and rGO support maintained their shapes up to $400^{\circ} \mathrm{C}$, whereas NPs were partially agglomerated and the rGO support was relatively damaged when the temperature reached $500{ }^{\circ} \mathrm{C}$. In addition, graphene oxide (GO) was used to investigate the support material effect on electrocatalysis. The as-synthesized NiO NPs/GO and its annealed product at $400{ }^{\circ} \mathrm{C}$, which is A-NiO NPs/GO, were also characterized by TEM with corresponding size distributions, as described in Figure S2. Similar to NiO NPs/rGO, as-synthesized NiO NPs/GO showed that monodispersed NiO NPs were anchored on the surface of the GO with an average size of $1.1 \mathrm{~nm}$ (see Figure S2a,b). After annealing at $400{ }^{\circ} \mathrm{C}, \mathrm{A}-\mathrm{NiO}$ NPs $/$ GO formed an increased NP size of $5.1 \mathrm{~nm}$ (see Figure S2c,d).

To investigate the crystallinity of the NPs, we conducted XRD analyses for the NiO $\mathrm{NPs} / \mathrm{rGO}$ and A-NiO NPs/rGO. However, as shown in Figure S3, there are no clear peaks either $\mathrm{Ni}$ or $\mathrm{NiO}$ for both catalysts. This is because the size of the NPs is too small to be observed, so a high angle annular dark field-scanning transmission electron microscopy (HAADF-STEM) analysis was performed for individual catalysts to verify the structure change of the NPs. The HAADF-STEM image shows multiple facets of an A-NiO NP anchored on the rGO surface (see Figure 2e). There are two distinguished areas with different crystallinity. The center of the NP (green dashed line area) shows (111) and (200) planes of Ni and the outer surface of the NP (yellow dashed line area) represents (111) and (200) planes of NiO. Moreover, fast Fourier transform (FFT) images were extracted from each area of Figure 2e. These images also support that single NP consists of separated phases of $\mathrm{Ni}$ (Figure 2f) and $\mathrm{NiO}$ (Figure 2g).

Furthermore, elemental analyses were conducted using EDS. As shown in Figure S4, the EDS spectrum of the A-NiO NPs/rGO confirms that it consists of carbon, oxygen, and nickel. To investigate spatial element distribution of the A-NiO NPs/rGO, HAADF-EDS mapping analyses were also performed (see Figure $2 \mathrm{~h}$ ). They clearly show that the NP is composed of $\mathrm{Ni}$ and $\mathrm{O}$ with almost the same distribution shape from the HAADF image of $\mathrm{NP}$, and also the NP is on the carbonaceous support with the homogeneous distribution of carbon. Remarkably, we could also observe the central part of the NP (red dashed line area) with Ni-rich and O-deficient areas in the A-NiO NPs/rGO. On the other hand, Figure S5a shows that oxygen is homogeneously dispersed in the NiO NPs/rGO. We believe that this outcome is from the partial reduction of NiO NPs surface during the annealing procedure of the A-NiO NPs/rGO.

For more clarification, we collected the selected area electron diffraction (SAED) of the A-NiO NPs/rGO (Figure 2i). The SAED shows several ring-shaped patterns at the center, which could be assigned to planes of the $C$ and Ni-related phases. The rGO (002) related pattern appears nearest to the center, and also $\mathrm{NiO}$ (111) related pattern is weakly detected, which is distinct from $\mathrm{Ni}$ (111). In addition, larger rings correspond to higher index facets of $\mathrm{Ni}$ and $\mathrm{NiO}$, which overlapped each other but could be distinguished as green dashed ring $(\mathrm{Ni})$ and yellow dashed ring $(\mathrm{NiO})$, respectively. Meanwhile, clear patterns of each phase were hardly seen in the NiO NPs/rGO (see Figure S5b). To this end, we might conclude that the A-NiO NPs/rGO was synthesized in a form of two compatible phases $(\mathrm{Ni}-\mathrm{NiO})$ on the carbonaceous support (rGO). 

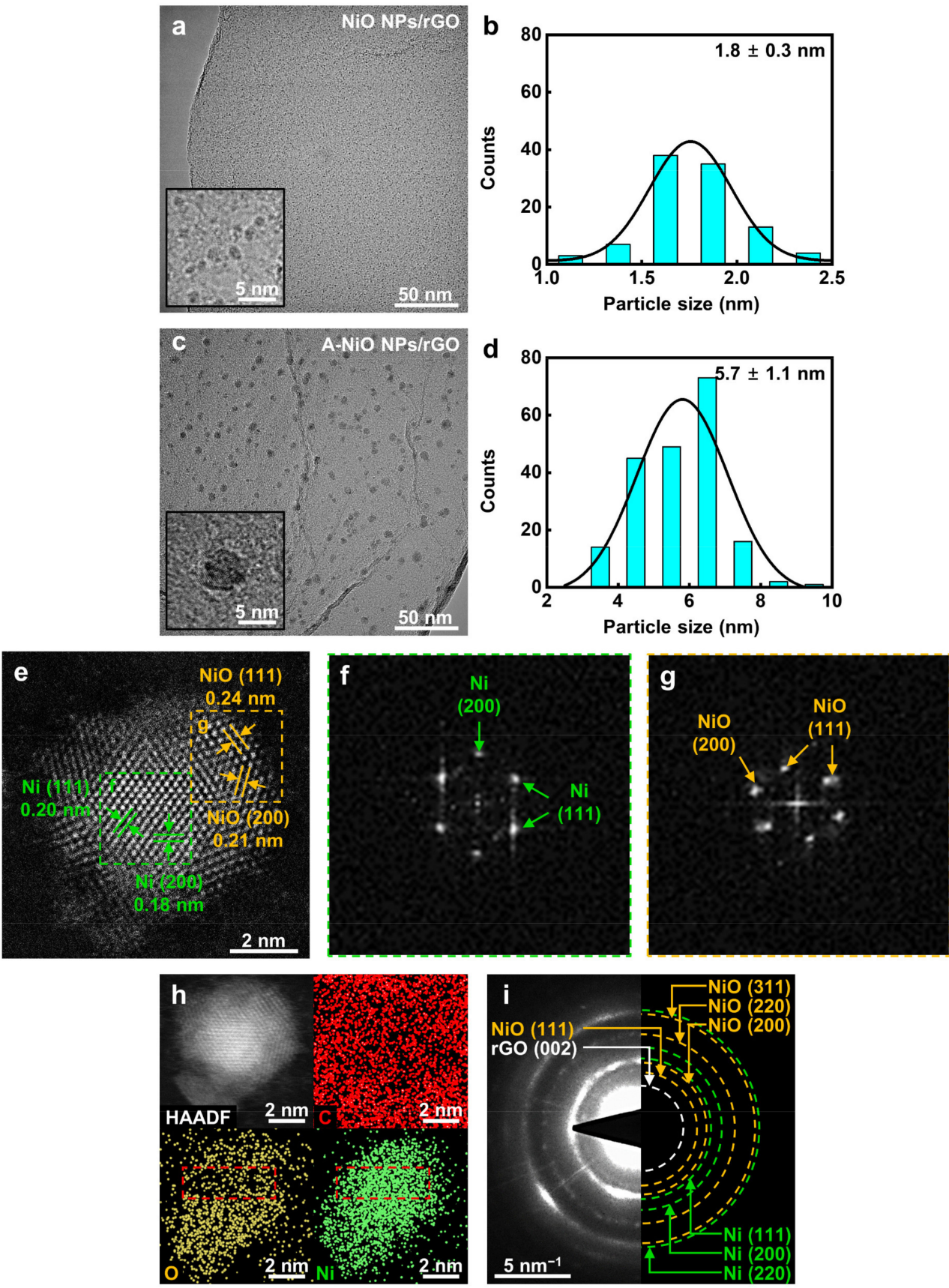

Figure 2. Morphology and structure characterizations. TEM images and corresponding particle size distribution of $(\mathbf{a}, \mathbf{b}) \mathrm{NiO} N P s / r G O$ and $(\mathbf{c}, \mathbf{d}) \mathrm{A}-\mathrm{NiO} \mathrm{NPs} / \mathrm{rGO}$. Insets of (a) and (c) are enlarged images. (e) HAADF-STEM image and $(\mathbf{f}, \mathbf{g})$ locally characterized FFT images of one Ni-NiO NP from A-NiO NPs/rGO. (h) HAADF-EDS mapping of the Ni-NiO NP from A-NiO NPs/rGO. (i) SAED image of A-NiO NPs/rGO.

To confirm the chemical states of the NiO NPs/rGO and the A-NiO NPs/rGO, we additionally performed X-ray photoelectron spectroscopy (XPS) analyses. First of all, the $\mathrm{C}$ 1s fine spectra of the NiO NPs/rGO and the A-NiO NPs/rGO are shown in Figure $3 a$. Both samples contain five deconvoluted peaks at 284.6, 286.0, 287.8, 289.4, and $291.4 \mathrm{eV}$, which correspond to $\mathrm{C}-\mathrm{C}, \mathrm{C}-\mathrm{O}, \mathrm{C}=\mathrm{O}, \mathrm{O}=\mathrm{C}-\mathrm{O}$, and $\pi-\pi$ satellite, respectively [35]. The $\mathrm{C}-\mathrm{C}$ bonding indicates carbon atoms in a conjugated lattice of the graphene layer, whereas the residual $\mathrm{C}-\mathrm{O}, \mathrm{C}=\mathrm{O}$, and $\mathrm{O}=\mathrm{C}-\mathrm{O}$ bondings originated from the epoxide, carbonyl, and carboxylate groups on the rGO surface. Moreover, including $\mathrm{C}-\mathrm{O}$ bonding, the peak intensities of oxygen-related functional groups are decreased after annealing of the $\mathrm{NiO}$ 
$\mathrm{NPs} / \mathrm{rGO}$, because of the reduction of the rGO. In addition, the $\mathrm{O} 1 \mathrm{~s}$ fine spectra of the $\mathrm{NiO}$ $\mathrm{NPs} / \mathrm{rGO}$ and the A-NiO NPs/rGO commonly present four peaks at 531.2, 532.0, 533.0, and $533.9 \mathrm{eV}$, which are related to $\mathrm{Ni}-\mathrm{OH} / \mathrm{O}=\mathrm{C}-\mathrm{O}, \mathrm{O}=\mathrm{C}, \mathrm{C}-\mathrm{OH}$, and $\mathrm{O}-\mathrm{C}$, respectively (see Figure 3b) [36]. Each peak reflects carboxylate, carbonyl, hydroxyl, and epoxide functional groups, which are well-matched with the outcomes of the $\mathrm{C} 1 \mathrm{~s}$ analysis. Additionally, the $\mathrm{Ni}-\mathrm{OH}$ peak is derived from adsorbed $\mathrm{OH}^{-}$species on $\mathrm{Ni}^{2+}$ surface [37]. Here, noticeably, a new peak appeared at $529.8 \mathrm{eV}$ in the case of the $\mathrm{A}-\mathrm{NiO} \mathrm{NPs} / \mathrm{rGO}$, which indicates lattice oxygen $\mathrm{Ni}-\mathrm{O}-\mathrm{Ni}$ [37]. It might be assumed that the crystalline $\mathrm{Ni}-\mathrm{O}$ bonding was formed during the annealing process, and it is consistent with previously presented TEM data.
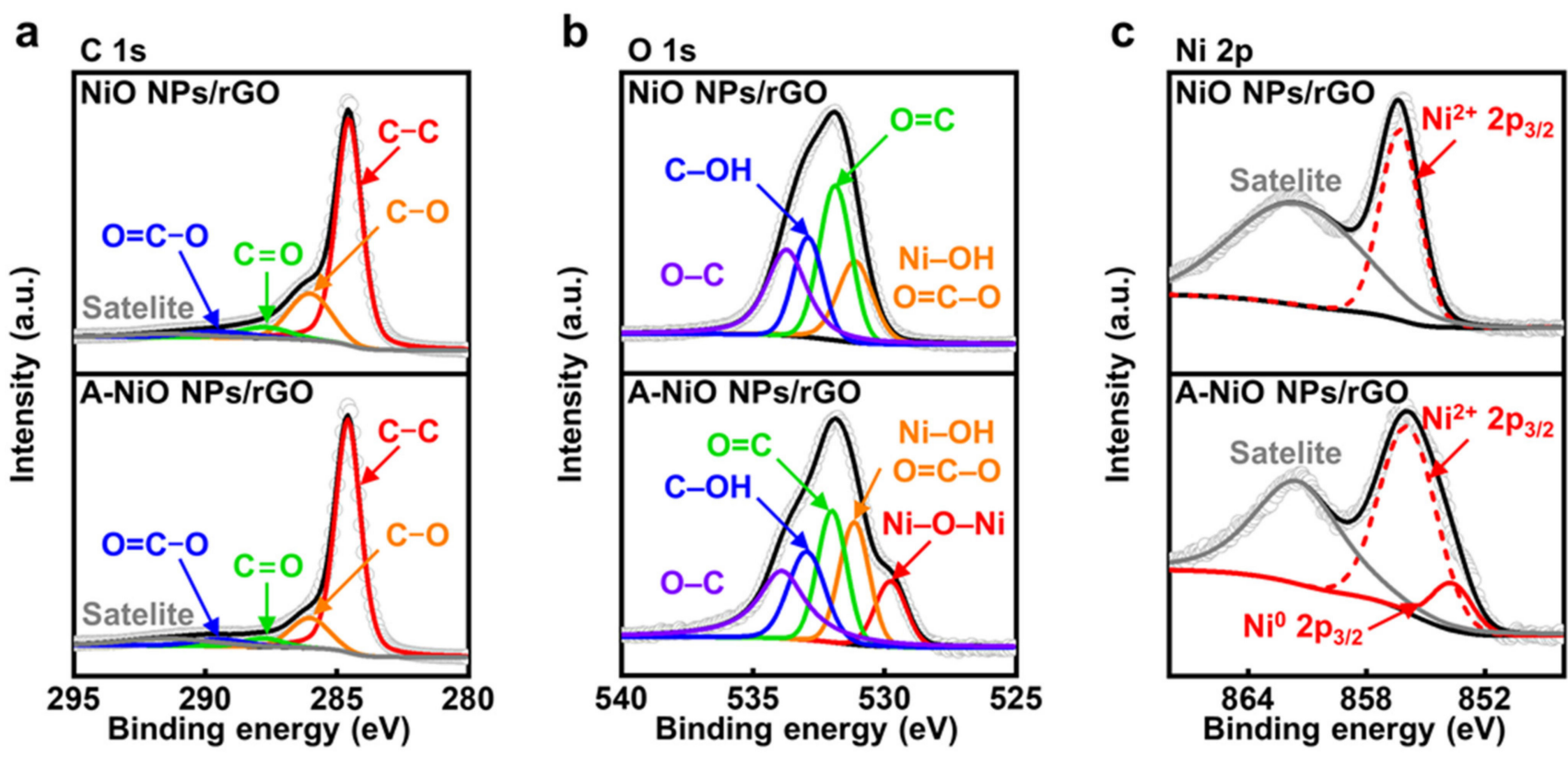

Figure 3. XPS characterizations for thermal annealing. XPS spectra of (a) C 1s, (b) O 1s, (c) Ni $2 \mathrm{p}_{3 / 2}$ for NiO NPs/rGO (upper) and A-NiO NPs/rGO (lower).

Finally, we compared Ni 2p fine spectra of the NiO NPs/rGO and the A-NiO NPs/rGO samples to determine the partial reduction of $\mathrm{NiO}$ after the annealing procedure as we observed from TEM analyses. As described in Figure 3c, both samples contain two common peaks of $\mathrm{Ni}^{2+} 2 \mathrm{p}_{3 / 2}$ and its satellite of the $\mathrm{NiO}$ at 856.0 and $861.5 \mathrm{eV}$, respectively [38]. On the other hand, the A-NiO NPs/rGO shows another peak at $853.6 \mathrm{eV}$, which corresponds to the $\mathrm{Ni}^{0} 2 \mathrm{p}_{3 / 2}$ state $[38,39]$. This outcome clearly supports the generation of metallic $\mathrm{Ni}$ phase after thermal reduction, and thereby, the co-existence of two phases of $\mathrm{Ni}$ in metallic and oxide states for the A-NiO NPs/rGO. Additionally, we also conducted XPS analyses for the NiO NPs/GO and the A-NiO NPs/GO to check the influence of the GO as a support material (see Figure S6). They show a relatively higher ratio of oxygen-containing carbon functional groups. However, except for those parts, they represent almost the same trends with the rGO used catalysts in $\mathrm{C} 1 \mathrm{~s}, \mathrm{O} 1 \mathrm{~s}$, and $\mathrm{Ni} 2 \mathrm{p}$ peaks before and after the annealing process.

\subsection{Electrochemical Measurements of the Catalysts}

After proving the co-existence of oxide and metallic phases in $\mathrm{Ni}$, we carried out electrochemical analyses for the A-NiO NPs/rGO with a three-electrode system in $1 \mathrm{M}$ $\mathrm{KOH}$ aqueous solution to evaluate the catalytic activity and durability of the HER performance. Figure 4a shows the LSV curves of the catalysts, and Figure $4 \mathrm{~b}$ represents their overpotentials at $10 \mathrm{~mA} \mathrm{~cm}^{-2}$ of current density (red dashed line) from the curves. In the case of the NiO NPs/rGO, $353 \mathrm{mV}$ is required to achieve $10 \mathrm{~mA} \mathrm{~cm}^{-2}$, while the A-NiO $\mathrm{NPs} / \mathrm{rGO}$ shows much lower overpotential as $201 \mathrm{mV}$, the lowest value compared to that 
of previously studied catalysts, which are from $205 \mathrm{mV}$ to $410 \mathrm{mV}$ vs. RHE (see Table S2). This might originate from the synergistic effect of the Ni-NiO dual-phase. Furthermore, the $\mathrm{NiO}$ NPs/GO and the A-NiO NPs/GO samples exhibit $453 \mathrm{mV}$ and $274 \mathrm{mV}$, respectively. Here, the annealed sample has a lower overpotential value than the as-synthesized sample, because of partial reduction of the NiO NPs. In general, the GO-supported materials have relatively higher overpotential values than that of rGO-supported materials and annealed samples with the same supporting materials have lower overpotential values than that of as-synthesized samples.

a

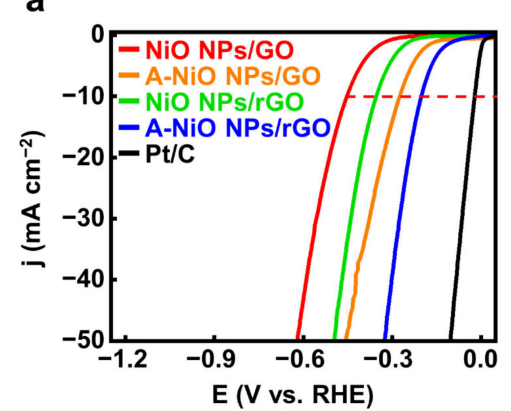

d

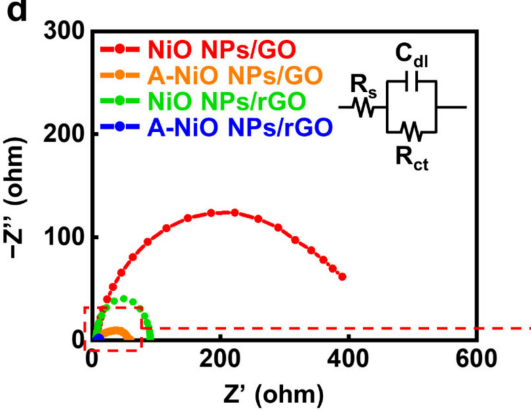

g

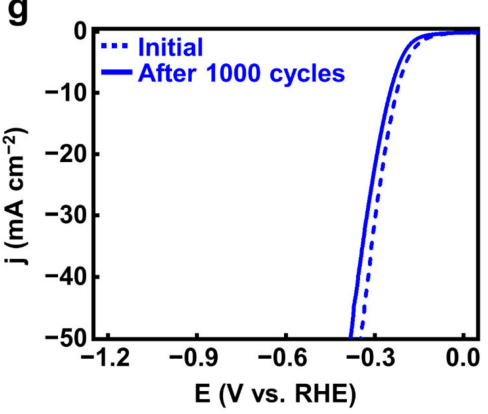

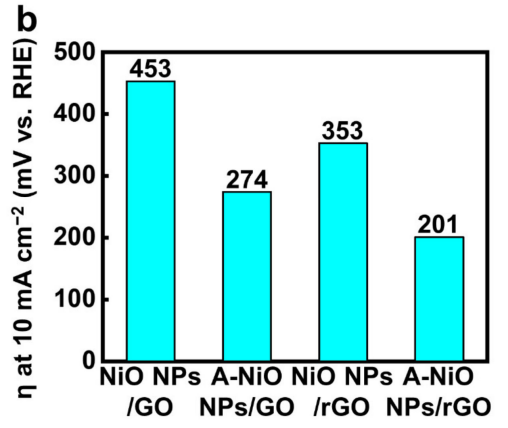

C

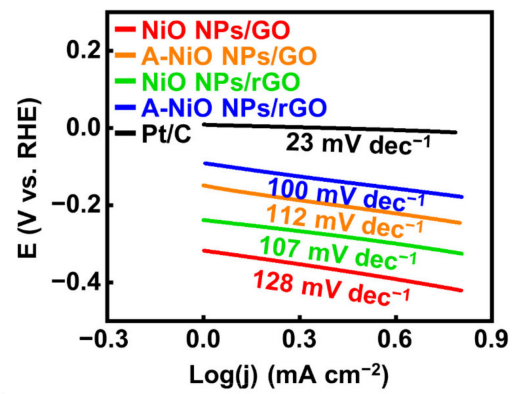

f
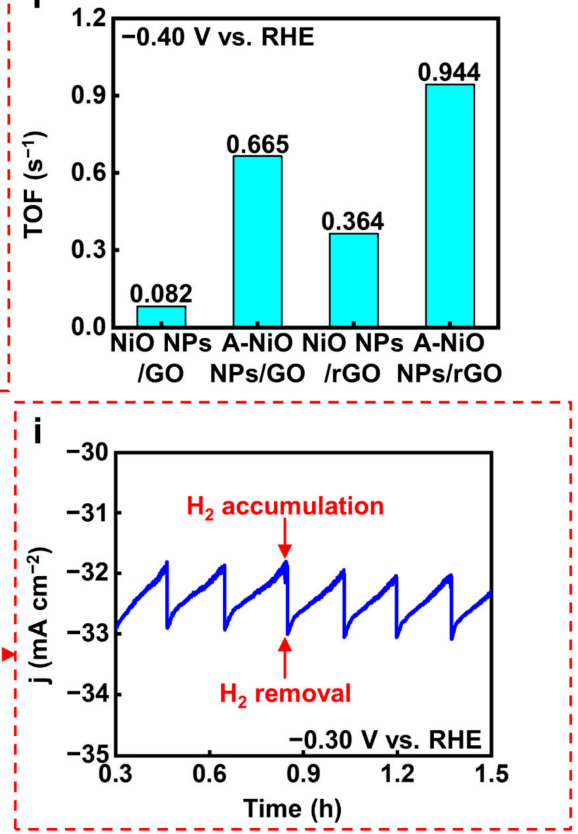

Figure 4. Electrochemical measurement for HER. (a) LSV curves for HER and (b) corresponding overpotentials at $10 \mathrm{~mA} \mathrm{~cm}^{-2}$ of $\mathrm{NiO} \mathrm{NPs} / \mathrm{GO}, \mathrm{A}-\mathrm{NiO} \mathrm{NPs} / \mathrm{GO}, \mathrm{NiO} \mathrm{NPs} / \mathrm{rGO}, \mathrm{A}-\mathrm{NiO} \mathrm{NPs} / \mathrm{rGO}$, and Pt/C in $1 \mathrm{M} \mathrm{KOH}$ at a scan rate of $5 \mathrm{mV} \mathrm{s}^{-1}$. (c) Tafel slopes of NiO NPs/GO, A-NiO NPs/GO, NiO NPs/rGO, A-NiO NPs/rGO, and Pt/C. (d) EIS curves and (e) enlarged data of NiO NPs/GO, A-NiO NPs/GO, NiO NPs/rGO, and A-NiO NPs/rGO at an overpotential of $-0.30 \mathrm{~V}$ vs RHE. Inset of (d) is the Randles circuit of the HER. (f) Histograms for TOF of NiO NPs/GO, A-NiO NPs/GO, $\mathrm{NiO} \mathrm{NPs} / \mathrm{rGO}$, and A-NiO NPs/rGO at $-0.40 \mathrm{~V}$ vs. RHE. (g) LSV curves of A-NiO NPs/rGO before and after 1000 cycles of durability test. (h) CA test of A-NiO NPs/rGO under an overpotential of $-0.30 \mathrm{~V}$ vs. RHE for $12 \mathrm{~h}$. (i) Zoomed in data from (h).

For detailed elucidation of the correlation between the catalytic activities and the annealing conditions, we carried out LSV for different annealing temperatures and different atmospheres. We determined that all of the annealed catalysts outperform the as-synthesized $\mathrm{NiO} \mathrm{NPs} / \mathrm{rGO}$ (see Figure S7a,b). The annealing temperature has an optimal HER activity at $400{ }^{\circ} \mathrm{C}$, implying the deterioration of performance from the aggregation of NPs and the decrease in active surface area on NPs by Ostwald ripening at the elevated temperature such as $500{ }^{\circ} \mathrm{C}$ (see Figure S1c,d). Furthermore, as shown in Figure S8a,b, we 
found that thermal annealing without $\mathrm{H}_{2}$ showed slightly higher overpotential $(243 \mathrm{mV}$ ) than $\mathrm{A}-\mathrm{NiO} \mathrm{NPs} / \mathrm{rGO}$, suggesting that hydrogen precursor partially reduces $\mathrm{NiO} \mathrm{NPs}$ (see Figure $3 \mathrm{c}$ ), and it affects the catalytic activity in HER. Additionally, Tafel slopes of the same materials confirm that the A-NiO NPs/rGO has the lowest value among Ni-based catalysts, $100 \mathrm{mV} \mathrm{dec}{ }^{-1}$. This implies that hydrogen adsorption and desorption on the surface of the A-NiO NPs/rGO affects the reaction rate more than water molecule dissociation. Meanwhile, the NiO NPs/GO (128 mV dec $\left.{ }^{-1}\right)$, A-NiO NPs/GO $\left(112 \mathrm{mV} \mathrm{dec}^{-1}\right)$, and NiO $\mathrm{NPs} / \mathrm{rGO}\left(107 \mathrm{mV} \mathrm{dec}^{-1}\right)$ showed higher slopes than the A-NiO NPs/rGO, suggesting that water dissociation still affects the whole reaction rate in HER, showing sluggish hydrogen evolution compared to the A-NiO NPs/rGO at the same potential (see Figure 4c). Furthermore, EIS analyses were performed to compare the charge transfer rates of the catalysts. There are three components that constitute a Randle circuit, as shown in the inset of Figure $4 \mathrm{~d}$ [40]. The solution resistance $\left(\mathrm{R}_{\mathrm{s}}\right)$ was measured at a high frequency of $100 \mathrm{kHz}$, and double-layer capacitance $\left(\mathrm{C}_{\mathrm{dl}}\right)$ appeared in the form of a semicircle as the frequency decreased. The charge transfer resistance $\left(R_{c t}\right)$ was estimated at a low frequency of $0.01 \mathrm{~Hz}$. More specifically, the catalyst has a fast charge transfer at the interface when it has a low $R_{c t}$ under constant $R_{s}$. The $R_{c t}$ values of the catalysts are displayed in Figure $4 d$,e and the $\mathrm{NiO} \mathrm{NPs} / \mathrm{GO}, \mathrm{A}-\mathrm{NiO} \mathrm{NPs} / \mathrm{GO}, \mathrm{NiO} \mathrm{NPs} / \mathrm{rGO}$, and A-NiO NPs/rGO are approximately $400,55,85$, and $10 \Omega$, respectively. Thus, the A-NiO NPs/rGO exhibits the lowest charge transfer resistance among these materials, which suggests that a faster chemical reaction could be achieved at the catalyst interface. In addition, TOF was calculated at $-0.40 \mathrm{~V}$ vs. RHE in order to evaluate HER efficiency, as described in Figure 4f. For the TOF calculation, the amount of Ni was determined by using ICP-OES, as shown in Table S1. We found that the weight ratios of each catalyst were $6.7,8.7,7.9$, and $14.2 \mathrm{wt} \%$ for the NiO NPs/GO, A-NiO NPs/GO, NiO NPs/rGO, and A-NiO NPs/rGO, respectively. The A-NiO NPs/rGO has the fastest rate of switching from hydrogen atoms to hydrogen molecules on its surface, with $0.944 \mathrm{~s}^{-1}$. In addition, the results indicate that active materials on the rGO have higher activity than when they are on the GO because oxygen-containing functional groups on the graphene support interfere with the conduction of electrons during the chemical reaction. It is well-matched with the results of the HER performances, which are described in Figure 4a. Furthermore, we estimated the mass-normalized catalytic activity by ICP-OES and LSV. Although the quantitative amount of the metal NPs was different for each catalyst, HER activity shows a consistent result, as displayed in Figure S9a, indicating that A-NiO $\mathrm{NPs} / \mathrm{rGO}$ exhibits the best performance among the non-precious metal-anchored catalysts.

For further characterization, we evaluated the long-term durability of $\mathrm{CV}$ and $\mathrm{CA}$. In Figure $4 \mathrm{~g}$, the LSV curve of the A-NiO NPs/rGO shows a negligible change between the initial state (blue dashed line) and after 1000 cycles curves (blue solid line), indicating that its catalytic activity was maintained in spite of repeated and prolonged redox reactions. Moreover, the TEM image and particle size distribution in Figure S10a,b show that the $\mathrm{NPs}$ are rarely aggregated or detached from rGO surface. This indicates that the A-NiO $\mathrm{NPs} / \mathrm{rGO}$ maintained its morphology after the durability test. We also investigated XPS for A-NiO NPs/rGO after the CV test, and found that both nickel and nickel oxide peaks are maintained after the durability test, as displayed in Figure S11. This means that two distinct phases are negligibly changed during the repeated redox reaction, confirming that $\mathrm{A}-\mathrm{NiO}$ $\mathrm{NPs} / \mathrm{rGO}$ has superior durability. Furthermore, CA data confirm its notable stability in alkaline media at $-0.30 \mathrm{~V}$ vs. RHE for over $12 \mathrm{~h}$ (see Figure $4 \mathrm{~h}$ ). Moreover, during CA measurement, we observed that hydrogen bubbles occurred on the GCE surface, which would block the interaction between the GCE surface and the electrolyte. The bubbles accumulated on the surface of GCE and burst, after then, the catalyst could contact the liquid electrolyte again for hydrogen generation. To this end, the graph has repeated zigzag patterns, as displayed in Figure 4i.

We also evaluated the OER performances of the catalysts compared to commercial $\mathrm{Ir} / \mathrm{C}$. Figure $5 \mathrm{a}$ shows the LSV curves of the catalysts and Figure $5 \mathrm{~b}$ represents their corresponding overpotentials at $10 \mathrm{~mA} \mathrm{~cm}^{-2}$ (red dashed line), respectively. As a reference 
sample, the commercial $\mathrm{Ir} / \mathrm{C}$ represents $332 \mathrm{mV}$ as the overpotential. The $\mathrm{NiO} \mathrm{NPs} / \mathrm{rGO}$ exhibits the lowest overpotential as $369 \mathrm{mV}$ compared to those of the A-NiO NPs/rGO as $397 \mathrm{mV}$, the A-NiO NPs/GO as $465 \mathrm{mV}$, and the NiO NPs/GO as $625 \mathrm{mV}$. It shows higher OER activity than previously reported catalysts, ranging from $390 \mathrm{mV}$ to $510 \mathrm{mV}$ vs. RHE (see Table S3). Additionally, small peaks near $1.40 \mathrm{~V}$ vs. RHE occur for the $\mathrm{NiO}$ $\mathrm{NPs} / \mathrm{rGO}$ and the A-NiO NPs/rGO. These peaks are originated from the change in $\mathrm{NiO}$ to $\mathrm{Ni}(\mathrm{OH})_{2}$ when exposed to the alkaline solution, and $\mathrm{Ni}(\mathrm{OH})_{2}$ is oxidized to $\mathrm{NiOOH}$ in the anodic potential [41]. Moreover, it implies that if the area of the peak becomes larger, the surface area of the catalyst will be increased, and thus, it will have a higher number of active sites in OER [42]. In fact, the NiO NPs/rGO shows the largest peak among all the measured catalysts, and it also matches well with the aforementioned results. Furthermore, as shown in Figure 5c, NiO NPs/rGO exhibits the lowest Tafel slope with $61 \mathrm{mV} \mathrm{dec}^{-1}$, which is lower than those of the A-NiO NPs $/ \mathrm{rGO}$ with $73 \mathrm{mV} \mathrm{dec}{ }^{-1}$, the A-NiO NPs/GO with $81 \mathrm{mV} \mathrm{dec}^{-1}$, the NiO NPs/GO with $168 \mathrm{mV} \mathrm{dec}^{-1}$, and the Ir/C with $74 \mathrm{mV} \mathrm{dec}^{-1}$. It also represents that hydroxyl ions are prone to adsorb on the $\mathrm{NiO}$ NPs/rGO surface and trigger oxygen evolution faster than other catalysts, resulting in less overpotential to achieve specific current density. Based on this outcome, we might regard that the $\mathrm{NiO} \mathrm{NPs} / \mathrm{rGO}$ has superior OER performance to all of the synthesized electrocatalysts. In addition, we conducted EIS measurements to compare the charge transfer resistance on the catalyst surface, as shown in Figure $5 \mathrm{~d}$,e. We found that the $\mathrm{NiO}$ NPs/rGO has the lowest $R_{\mathrm{ct}}$ with approximately $100 \Omega$, and the resistance increases in the cases of the A-NiO NPs/rGO with $150 \Omega$, the A-NiO NPs/GO with $2300 \Omega$, and the NiO NPs/GO with $4000 \Omega$. These results indicate that the NiO NPs/rGO has surpassing charge transfer characteristics on the surface. Accordingly, the NiO NPs/rGO demonstrates the highest oxygen turnover rate, as shown in Figure 5f. The TOF calculation for OER also confirms that the NiO NPs/rGO could convert hydroxyl ions to oxygen molecules rapidly under a given potential of $1.63 \mathrm{~V}$ vs. RHE. In addition, we also measured the LSV of the catalysts, which are annealed at different temperatures, and it could be considered that the annealing procedure would not promote OER activity (see Figure S7c,d), and thermal annealing without $\mathrm{H}_{2}$ shows better activity than $\mathrm{H}_{2}$-introduced A-NiO NPs/rGO (see Figure S8c,d). Moreover, mass-normalized activity in OER also corresponds with the geometrically normalized data, as shown in Figure S9b. For further characterization, we analyzed the long-term durability of the OER by CV and CA. As shown in Figure $5 g$, an LSV curve after 1000 cycles (green solid line) exhibits a decreased peak at $1.40 \mathrm{~V}$ vs. RHE, but a slightly higher activity than the initial curve (green dashed line), indicating that its stability was maintained through repeated redox reactions. The CA graph in Figure $5 \mathrm{~h}$ shows that the NiO NPs/rGO retained its activity over $12 \mathrm{~h}$ at $1.53 \mathrm{~V}$ vs. RHE, which suggests its high durability performance in an alkaline solution.

\subsection{Correlation between the Reaction Mechanism and Electrochemical Performances}

The electrochemical results on the HER and OER could be more specifically explained by the mechanisms described in Figure S12. In the case of the HER in alkaline media, it is necessary to dissociate water molecules because of hydrogen intermediates that participate in the generation of hydrogen molecules. The water molecules are separated into hydroxide ions and hydrogen ions due to the presence of $\mathrm{NiO}$, and then hydrogen species are adsorbed on the metallic Ni surface. This step is called the Volmer step [25,43]. As the next step, hydrogen molecules could be generated from the adsorbed hydrogen species in two ways. One way is called the Heyrovsky step, where the adsorbed hydrogens, water molecules, and electrons could react together to produce gaseous $\mathrm{H}_{2}$ and hydroxide ions [44]. The other way is called the Tafel step, where the interaction of two adsorbed hydrogen intermediates could form $\mathrm{H}_{2}$ molecules [45]. The phases of $\mathrm{Ni}$ that take the lead in each reaction are separated, which implies that the reaction rate could be improved when two metallic and oxide Ni phases could co-exist. More precisely, it is harder for $\mathrm{H}^{+}$ions to attach and detach on the catalyst if there is only $\mathrm{NiO}$, whereas water molecules could not dissociate well 
when only metallic $\mathrm{Ni}$ is present. To this end, the partially reduced $\mathrm{NiO}$ is preferred for the high activity of HER. On the other hand, negatively charged species such as hydroxyl ions and oxygen-based intermediates are mainly involved in OER, as shown in Figure S13 [24]. Thus, it is more favorable to use $\mathrm{NiO}$ than metallic $\mathrm{Ni}$ due to electrostatic attraction between the species and $\mathrm{Ni}^{2+}$. Moreover, small-size NPs have a higher active surface area, resulting in better performance in OER. Based on these mechanisms, NiO NPs could be utilized in both reactions by controlling their interface.

a
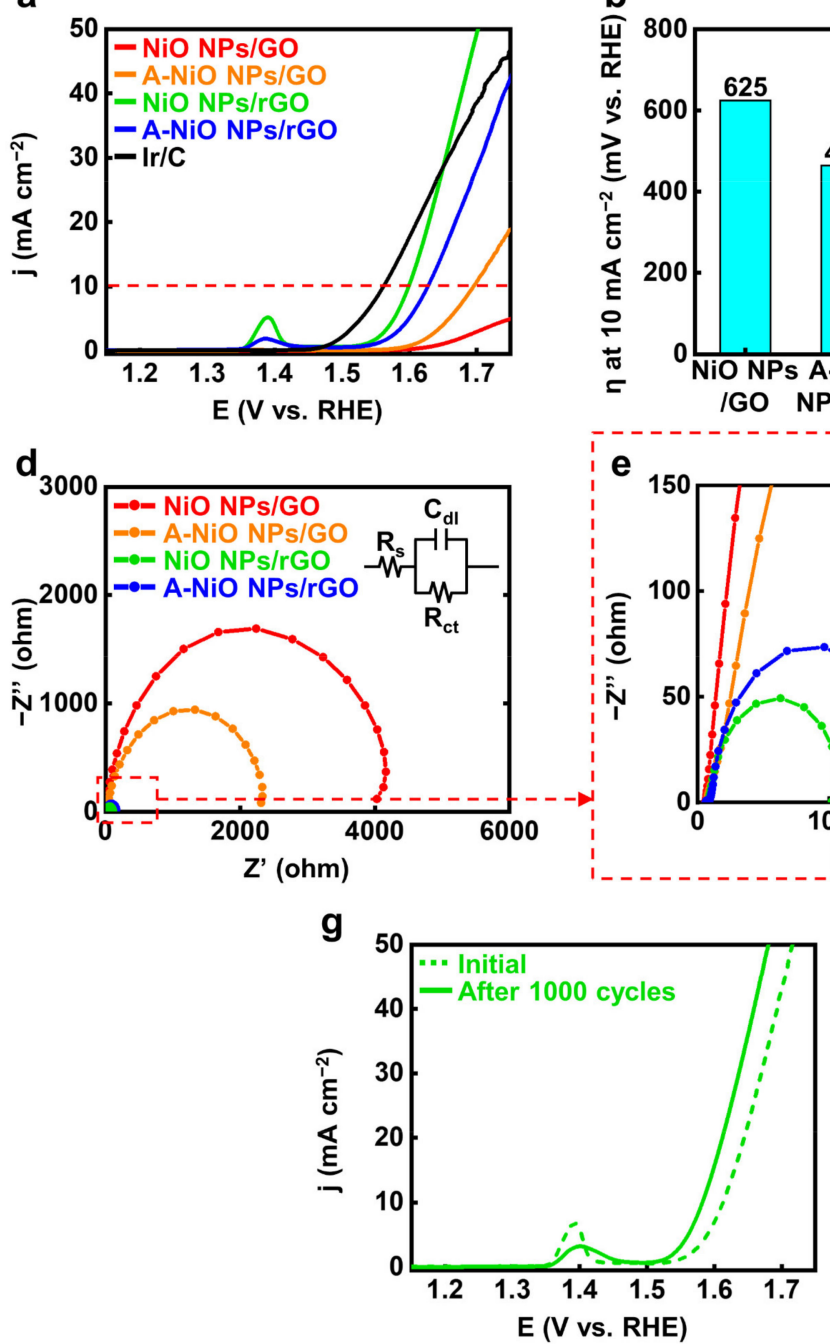

C

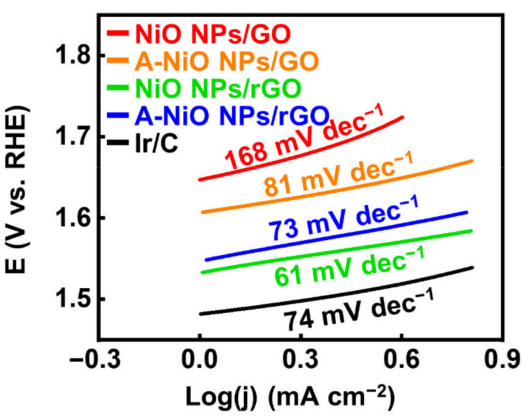

f

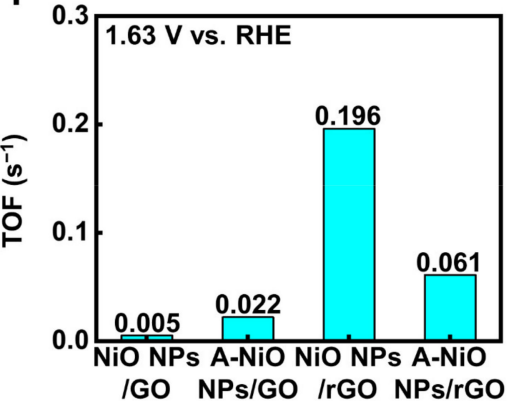

\section{h}

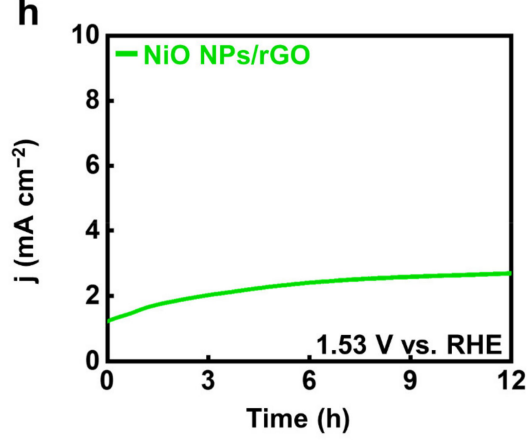

Figure 5. Electrochemical measurements for OER. (a) LSV curves for OER and (b) corresponding overpotentials at $10 \mathrm{~mA} \mathrm{~cm}^{-2}$ of NiO NPs/GO, A-NiO NPs/GO, NiO NPs/rGO, A-NiO NPs/rGO, and Ir/C in $1 \mathrm{M}$ KOH at a scan rate of $5 \mathrm{mV} \mathrm{s}^{-1}$. (c) Tafel slopes of NiO NPs/GO, A-NiO NPs/GO, NiO NPs/rGO, A-NiO NPs/rGO, and Ir/C. (d) EIS curves and (e) enlarged data of NiO NPs/GO, A-NiO NPs/GO, NiO NPs/rGO, and A-NiO NPs/rGO at an overpotential of $1.53 \mathrm{~V}$ vs RHE. Inset of (d) is the Randles circuit of the OER. (f) Histograms for TOF of NiO NPs/GO, A-NiO NPs/GO, NiO $\mathrm{NPs} / \mathrm{rGO}$, and A-NiO NPs/rGO at $1.63 \mathrm{~V}$ vs. RHE. (g) LSV curves of A-NiO NPs/rGO before and after 1000 cycles for durability test. (h) CA test of A-NiO NPs/rGO under an overpotential of $1.53 \mathrm{~V}$ vs. RHE for $12 \mathrm{~h}$.

\subsection{Overall Water Splitting}

Finally, we performed a full-cell test using a two-electrode cell configuration in $1 \mathrm{M}$ $\mathrm{KOH}$ with the A-NiO NPs/rGO as the negative electrode and the $\mathrm{NiO} \mathrm{NPs} / \mathrm{rGO}$ as the positive electrode by coating the catalyst ink on the Ni foam. For comparison, $\mathrm{Pt} / \mathrm{C}$ and Ir/C were used as the cathode and anode under the same conditions, respectively. As shown in Video S1, oxygen bubbles are generated from the anode coated with $\mathrm{NiO}$ 
NPs/rGO (left side), and hydrogen bubbles are released from the cathode coated with A-NiO NPs/rGO (right side). Figure 6a shows that noble metal-based catalysts have $\sim 1.58 \mathrm{~V}$ of potential at $10 \mathrm{~mA} \mathrm{~cm}{ }^{-2}$, whereas the A-NiO NPs/rGO in the cathode and the $\mathrm{NiO} \mathrm{NPs} / \mathrm{rGO}$ in the anode demonstrates $\sim 1.82 \mathrm{~V}$ at the same condition. In addition, the long-term durability of our non-precious catalysts was evaluated for $12 \mathrm{~h}$ under a constant potential of $2.00 \mathrm{~V}$ (see Figure $6 \mathrm{~b}$ ). It was observed that the current density remained almost unchanged while maintaining approximately $20 \mathrm{~mA} \mathrm{~cm}{ }^{-2}$ during measurement, confirming its stability for overall water splitting.

a

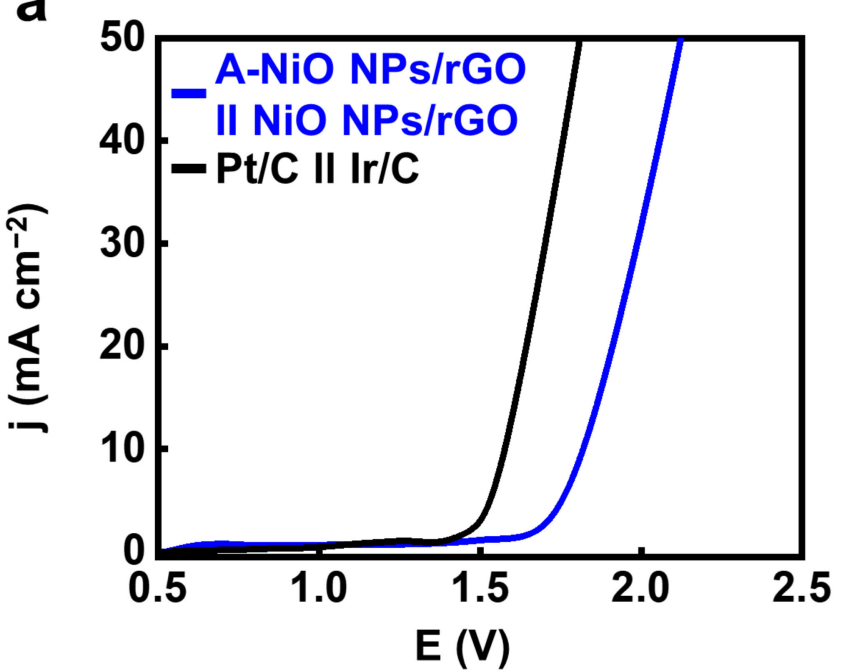

b

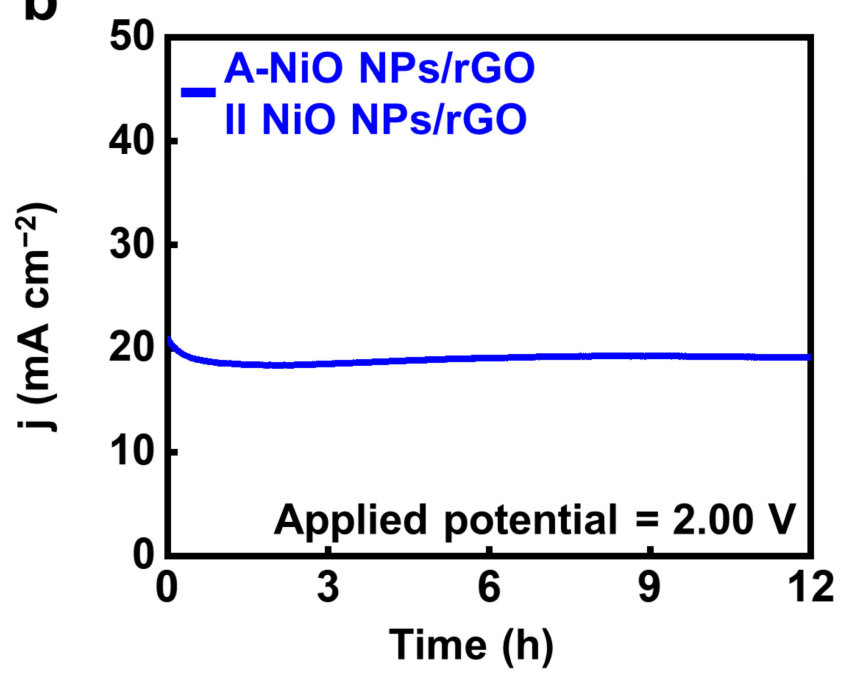

Figure 6. Overall water splitting test. (a) LSV curves of A-NiO NPs/rGO $\| \mathrm{NiO}$ NPs/rGO and Pt/C $\| \mathrm{Ir} / \mathrm{C}$ in $1 \mathrm{M} \mathrm{KOH}$ at $5 \mathrm{mV} \mathrm{s}^{-1}$ in a two-electrode system. (b) CA data for long-term durability at an applied potential of $2.00 \mathrm{~V}$ for $12 \mathrm{~h}$.

\section{Conclusions}

In summary, we synthesized NiO NPs on the rGO surface by the facile microwaveassisted method and controlled their interface through thermal reduction. The surface of NPs changed from oxidized $\mathrm{NiO}$ to partially metallic $\mathrm{Ni}$, resulting in two distinct coexisting $\mathrm{Ni}-\mathrm{NiO}$ phases. It promoted reaction rates for hydrogen evolution in alkaline media by showing synergistic effects, including that $\mathrm{NiO}$ facilitates dissociation of water molecules and Ni takes part in hydrogen adsorption/desorption. On the other hand, only $\mathrm{NiO}$ was beneficial to OER due to the interaction between the catalyst and negatively charged reactants. The TEM and XPS results demonstrated the change of the surface state of the NPs with the appearance of the metallic Ni phase. Moreover, electrochemical measurements could support the previously mentioned theoretical mechanism. The A-NiO $\mathrm{NPs} / \mathrm{rGO}$ had $201 \mathrm{mV}$ to reach a current density of $10 \mathrm{~mA} \mathrm{~cm}^{-2}$ in HER, which is much lower than NiO NPs/rGO (353 mV). On the other hand, as-synthesized NiO NPs/rGO could achieve only $369 \mathrm{mV}$ of overpotential under the same current density, which is higher activity than that of the A-NiO NPs/rGO $(397 \mathrm{mV})$ in OER. Furthermore, the A-NiO NPs/rGO maintained its morphology and structure over 1000 repeated redox cycles and under constant potential for $12 \mathrm{~h}$. Finally, we applied each catalyst selectively into an overall water splitting system and confirmed their full cell capability. From these results, the A-NiO NPs/rGO and NiO NPs/rGO could be possible candidates to replace precious metal-based electrocatalysts. This research could promote practical applications of alkaline water electrolysis technology. 
Supplementary Materials: The following are available online at https: / www.mdpi.com/article/ 10.3390/nano11123379/s1, TOF calculation, Figure S1: TEM images and corresponding particle size distribution of $(\mathrm{a}, \mathrm{b}) \mathrm{A}-\mathrm{NiO} \mathrm{NPs} / \mathrm{rGO}\left(300^{\circ} \mathrm{C}\right)$ and $(\mathrm{c}, \mathrm{d}) \mathrm{A}-\mathrm{NiO} \mathrm{NPs} / \mathrm{rGO}\left(500^{\circ} \mathrm{C}\right)$. Inset images of (a) and (c) are enlarged views, respectively. Figure S2: TEM images and corresponding particle size distribution of $(\mathrm{a}, \mathrm{b}) \mathrm{NiO} \mathrm{NPs} / \mathrm{GO}$ and $(\mathrm{c}, \mathrm{d}) \mathrm{A}-\mathrm{NiO} \mathrm{NPs} / \mathrm{GO}$. Inset images of $(\mathrm{a})$ and $(\mathrm{c})$ are enlarged views, respectively. Figure S3: XRD spectra of the NiO NPs/rGO and A-NiO NPs/rGO. Figure S4: (a) EDS spectrum of A-NiO NPs/rGO, (b) enlarged view of (a). Detected Cu peaks were originated from the $\mathrm{Cu}$ grid. Figure S5: (a) EDS mapping and (b) SAED image of NiO NPs/rGO. Figure S6: XPS spectra of (a) C 1s, (b) O 1s, (c) Ni 2 $p_{3 / 2}$ for NiO NPs/GO (upper) and A-NiO NPs/GO (lower). Figure S7: LSV curves and corresponding overpotential histograms at $10 \mathrm{~mA} \mathrm{~cm}^{-2}$ in $(\mathrm{a}, \mathrm{b}) \mathrm{HER}$ and $(\mathrm{c}, \mathrm{d})$ OER with different annealing temperature. Figure S8: LSV curves and corresponding overpotential histograms at $10 \mathrm{~mA} \mathrm{~cm}^{-2}$ in $(\mathrm{a}, \mathrm{b})$ HER and $(\mathrm{c}, \mathrm{d})$ OER with different annealing atmosphere. Figure S9: LSV curves of the catalysts which are mass-normalized in (a) HER and (b) OER. Figure S10. (a) TEM image and (b) corresponding particle size distribution of A-NiO $\mathrm{NPs} / \mathrm{rGO}$ after durability test. Figure S11. XPS spectra of $\mathrm{Ni} 2 \mathrm{p}_{3 / 2}$ for A-NiO NPs/rGO at an initial state (upper) and after durability test (lower). Figure S12: Schematic illustration of HER mechanism for Ni species in alkaline media. Figure S13: Schematic illustration of OER mechanism for Ni species in alkaline media. Table S1: ICP-OES data of catalysts. Table S2: Collected data of transition metal-carbonaceous support hybrid catalysts for HER. Table S3: Collected data of transition metal-carbonaceous support hybrid catalysts for OER. Video S1: Overall water splitting and gas generation by $\mathrm{NiO} \mathrm{NPs} / \mathrm{rGO}$ at the anode and $\mathrm{A}-\mathrm{NiO} \mathrm{NPs} / \mathrm{rGO}$ at the cathode.

Author Contributions: Conceptualization, J.W.L.; analysis, C.-S.K.; data curation, experimental methodology, investigation, data visualization, manuscript writing, S.G.J.; manuscript editing, S.G.J., S.J.K., and J.W.L.; review, C.-S.K., S.J.K., and J.W.L.; funding acquisition, supervision, project administration, J.W.L. All authors have read and agreed to the published version of the manuscript.

Funding: This research was supported by Nano-Material Technology Development Program (20090082580) through the National Research Foundation of Korea (NRF-2017M3A7B4049466, NRF2020R1C1C1013900, 2021R1A6A3A01086971) funded by the Ministry of Science, ICT and Future Planning, and by the Ministry of Trade, Industry and Energy (20016181).

Data Availability Statement: Data are contained within the article or Supplementary Materials.

Conflicts of Interest: The authors declare no conflict of interest.

\section{References}

1. Schlapbach, L.; Züttel, A. Hydrogen-storage materials for mobile applications. Nature 2001, 414, 353-358. [CrossRef] [PubMed]

2. Dincer, I.; Acar, C. Review and evaluation of hydrogen production methods for better sustainability. Int. J. Hydrogen Energy 2015, 40, 11094-11111. [CrossRef]

3. Turner, J.A. Sustainable hydrogen production. Science 2004, 305, 972-974. [CrossRef]

4. Holladay, J.D.; Hu, J.; King, D.L.; Wang, Y. An overview of hydrogen production technologies. Catal. Today 2009, 139, 244-260. [CrossRef]

5. Lee, D.-Y.; Elgowainy, A.; Dai, Q. Life cycle greenhouse gas emissions of hydrogen fuel production from chlor-alkali processes in the United States. Appl. Energy 2018, 217, 467-479. [CrossRef]

6. Lee, D.-Y.; Elgowainy, A. By-product hydrogen from steam cracking of natural gas liquids (NGLs): Potential for large-scale hydrogen fuel production, life-cycle air emissions reduction, and economic benefit. Int. J. Hydrogen Energy 2018, 43, 20143-20160. [CrossRef]

7. Zou, X.; Zhang, Y. Noble metal-free hydrogen evolution catalysts for water splitting. Chem. Soc. Rev. 2015, 44, 5148-5180. [CrossRef]

8. Nocera, D.G. The artificial leaf. Acc. Chem. Res. 2012, 45, 767-776. [CrossRef]

9. McCrory, C.C.; Jung, S.; Peters, J.C.; Jaramillo, T.F. Benchmarking heterogeneous electrocatalysts for the oxygen evolution reaction. J. Am. Chem. Soc. 2013, 135, 16977-16987. [CrossRef]

10. McCrory, C.C.; Jung, S.; Ferrer, I.M.; Chatman, S.M.; Peters, J.C.; Jaramillo, T.F. Benchmarking hydrogen evolving reaction and oxygen evolving reaction electrocatalysts for solar water splitting devices. J. Am. Chem. Soc. 2015, 137, 4347-4357. [CrossRef] [PubMed]

11. Seh, Z.W.; Kibsgaard, J.; Dickens, C.F.; Chorkendorff, I.; Nørskov, J.K.; Jaramillo, T.F. Combining theory and experiment in electrocatalysis: Insights into materials design. Science 2017, 355, aad4998. [CrossRef] [PubMed]

12. Wang, J.; Yue, X.; Yang, Y.; Sirisomboonchai, S.; Wang, P.; Ma, X.; Abudula, A.; Guan, G. Earth-abundant transition-metal-based bifunctional catalysts for overall electrochemical water splitting: A review. J. Alloy. Compd. 2020, 819, 153346. [CrossRef] 
13. Shang, X.; Tang, J.-H.; Dong, B.; Sun, Y. Recent advances of nonprecious and bifunctional electrocatalysts for overall water splitting. Sustain. Energy Fuels 2020, 4, 3211-3228. [CrossRef]

14. Zeng, K.; Zhang, D. Recent progress in alkaline water electrolysis for hydrogen production and applications. Prog. Energy Combust. Sci. 2010, 36, 307-326. [CrossRef]

15. Vij, V.; Sultan, S.; Harzandi, A.M.; Meena, A.; Tiwari, J.N.; Lee, W.-G.; Yoon, T.; Kim, K.S. Nickel-based electrocatalysts for energyrelated applications: Oxygen reduction, oxygen evolution, and hydrogen evolution reactions. ACS Catal. 2017, 7, 7196-7225. [CrossRef]

16. Guo, H.; Youliwasi, N.; Zhao, L.; Chai, Y.; Liu, C. Carbon-encapsulated nickel-cobalt alloys nanoparticles fabricated via new post-treatment strategy for hydrogen evolution in alkaline media. Appl. Surf. Sci. 2018, 435, 237-246. [CrossRef]

17. Park, S.-W.; Kim, I.; Oh, S.-I.; Kim, J.-C.; Kim, D.-W. Carbon-encapsulated NiFe nanoparticles as a bifunctional electrocatalyst for high-efficiency overall water splitting. J. Catal. 2018, 366, 266-274. [CrossRef]

18. Yan, J.; Kong, L.; Ji, Y.; White, J.; Li, Y.; Zhang, J.; An, P.; Liu, S.; Lee, S.-T.; Ma, T. Single atom tungsten doped ultrathin $\alpha-\mathrm{Ni}(\mathrm{OH})_{2}$ for enhanced electrocatalytic water oxidation. Nat. Commun. 2019, 10, 2149. [CrossRef]

19. Jiang, N.; Tang, Q.; Sheng, M.; You, B.; Jiang, D.-E.; Sun, Y. Nickel sulfides for electrocatalytic hydrogen evolution under alkaline conditions: A case study of crystalline NiS, $\mathrm{NiS}_{2}$, and $\mathrm{Ni}_{3} \mathrm{~S}_{2}$ nanoparticles. Catal. Sci. Technol. 2016, 6, 1077-1084. [CrossRef]

20. Hao, S.; Liu, J.; Cao, Q.; Zhao, Y.; Zhao, X.; Pei, K.; Zhang, J.; Chen, G.; Che, R. In-situ electrochemical pretreatment of hierarchical $\mathrm{Ni}_{3} \mathrm{~S}_{2}$-based electrocatalyst towards promoted hydrogen evolution reaction with low overpotential. J. Colloid Interface Sci. 2020, 559, 282-290. [CrossRef]

21. Wu, H.; Lu, X.; Zheng, G.; Ho, G.W. Topotactic Engineering of Ultrathin 2D Nonlayered Nickel Selenides for Full Water Electrolysis. Adv. Energy Mater. 2018, 8, 1702704. [CrossRef]

22. Jiang, P.; Liu, Q.; Sun, $\mathrm{X} . \mathrm{NiP}_{2}$ nanosheet arrays supported on carbon cloth: An efficient $3 \mathrm{D}$ hydrogen evolution cathode in both acidic and alkaline solutions. Nanoscale 2014, 6, 13440-13445. [CrossRef]

23. Cao, Q.; Hao, S.; Wu, Y.; Pei, K.; You, W.; Che, R. Interfacial charge redistribution in interconnected network of $\mathrm{Ni}_{2} \mathrm{P}-\mathrm{Co}_{2} \mathrm{P}$ boosting electrocatalytic hydrogen evolution in both acidic and alkaline conditions. Chem. Eng. J. 2021, 424, 130444. [CrossRef]

24. Gong, M.; Zhou, W.; Tsai, M.-C.; Zhou, J.; Guan, M.; Lin, M.-C.; Zhang, B.; Hu, Y.; Wang, D.-Y.; Yang, J. Nanoscale nickel oxide/nickel heterostructures for active hydrogen evolution electrocatalysis. Nat. Commun. 2014, 5, 4695. [CrossRef]

25. Zhao, L.; Zhang, Y.; Zhao, Z.; Zhang, Q.-H.; Huang, L.-B.; Gu, L.; Lu, G.; Hu, J.-S.; Wan, L.-J. Steering elementary steps towards efficient alkaline hydrogen evolution via size-dependent $\mathrm{Ni} / \mathrm{NiO}$ nanoscale heterosurfaces. Natl. Sci. Rev. 2020, 7, 27-36. [CrossRef]

26. Peigney, A.; Laurent, C.; Flahaut, E.; Bacsa, R.; Rousset, A. Specific surface area of carbon nanotubes and bundles of carbon nanotubes. Carbon 2001, 39, 507-514. [CrossRef]

27. Bolotin, K.I.; Sikes, K.J.; Jiang, Z.; Klima, M.; Fudenberg, G.; Hone, J.E.; Kim, P.; Stormer, H. Ultrahigh electron mobility in suspended graphene. Solid State Commun. 2008, 146, 351-355. [CrossRef]

28. Li, D.; Kaner, R.B. Graphene-based materials. Science 2008, 320, 1170-1171. [CrossRef] [PubMed]

29. Xu, C.; Wang, X.; Zhu, J. Graphene-Metal particle nanocomposites. J. Phys. Chem. C 2008, 112, 19841-19845. [CrossRef]

30. Mayrhofer, K.J.J.; Wiberg, G.K.H.; Arenz, M. Impact of Glass Corrosion on the Electrocatalysis on Pt Electrodes in Alkaline Electrolyte. J. Electrochem. Soc. 2008, 155, P1. [CrossRef]

31. Danilovic, N.; Subbaraman, R.; Strmcnik, D.; Chang, K.-C.; Paulikas, A.P.; Stamenkovic, V.R.; Markovic, N.M. Enhancing the Alkaline Hydrogen Evolution Reaction Activity through the Bifunctionality of $\mathrm{Ni}(\mathrm{OH})_{2} /$ Metal Catalysts. Angew. Chem. Int. Ed. 2012, 51, 12495-12498. [CrossRef]

32. Gong, M.; Wang, D.-Y.; Chen, C.-C.; Hwang, B.-J.; Dai, H. A mini review on nickel-based electrocatalysts for alkaline hydrogen evolution reaction. Nano Res. 2016, 9, 28-46. [CrossRef]

33. Suen, N.-T.; Hung, S.-F.; Quan, Q.; Zhang, N.; Xu, Y.-J.; Chen, H.M. Electrocatalysis for the oxygen evolution reaction: Recent development and future perspectives. Chem. Soc. Rev. 2017, 46, 337-365. [CrossRef]

34. Hansen, T.W.; DeLaRiva, A.T.; Challa, S.R.; Datye, A.K. Sintering of catalytic nanoparticles: Particle migration or Ostwald ripening? Acc. Chem. Res. 2013, 46, 1720-1730. [CrossRef] [PubMed]

35. Stankovich, S.; Dikin, D.A.; Piner, R.D.; Kohlhaas, K.A.; Kleinhammes, A.; Jia, Y.; Wu, Y.; Nguyen, S.T.; Ruoff, R.S. Synthesis of graphene-based nanosheets via chemical reduction of exfoliated graphite oxide. Carbon 2007, 45, 1558-1565. [CrossRef]

36. Al-Gaashani, R.; Najjar, A.; Zakaria, Y.; Mansour, S.; Atieh, M. XPS and structural studies of high quality graphene oxide and reduced graphene oxide prepared by different chemical oxidation methods. Ceram. Int. 2019, 45, 14439-14448. [CrossRef]

37. Dupin, J.-C.; Gonbeau, D.; Vinatier, P.; Levasseur, A. Systematic XPS studies of metal oxides, hydroxides and peroxides. Phys. Chem. Chem. Phys. 2000, 2, 1319-1324. [CrossRef]

38. Zhang, W.; Li, B. Electrochemical properties and XPS analysis of Ni-B/SiC nanocomposite coatings. Int. J. Electrochem. Sci. 2018, 13, 3516-3526. [CrossRef]

39. Li, H.; Li, H.; Dai, W.; Qiao, M. Preparation of the Ni-B amorphous alloys with variable boron content and its correlation to the hydrogenation activity. Appl. Catal. A Gen. 2003, 238, 119-130. [CrossRef]

40. Bard, A.J.; Faulkner, L.R. Electrochemical Methods: Fundamentals and Applications, 2nd ed.; John Wiley \& Sons: New York, NY, USA, 2001. 
41. Trotochaud, L.; Ranney, J.K.; Williams, K.N.; Boettcher, S.W. Solution-cast metal oxide thin film electrocatalysts for oxygen evolution. J. Am. Chem. Soc. 2012, 134, 17253-17261. [CrossRef] [PubMed]

42. Nardi, K.L.; Yang, N.; Dickens, C.F.; Strickler, A.L.; Bent, S.F. Creating Highly Active Atomic Layer Deposited NiO Electrocatalysts for the Oxygen Evolution Reaction. Adv. Energy Mater. 2015, 5, 1500412. [CrossRef]

43. Strmcnik, D.; Lopes, P.P.; Genorio, B.; Stamenkovic, V.R.; Markovic, N.M. Design principles for hydrogen evolution reaction catalyst materials. Nano Energy 2016, 29, 29-36. [CrossRef]

44. Vilekar, S.A.; Fishtik, I.; Datta, R. Kinetics of the Hydrogen Electrode Reaction. J. Electrochem. Soc. 2010, 157, B1040. [CrossRef]

45. Skúlason, E.; Tripkovic, V.; Björketun, M.E.; Gudmundsdóttir, S.; Karlberg, G.; Rossmeisl, J.; Bligaard, T.; Jónsson, H.; Nørskov, J.K. Modeling the Electrochemical Hydrogen Oxidation and Evolution Reactions on the Basis of Density Functional Theory Calculations. J. Phys. Chem. C 2010, 114, 18182-18197. [CrossRef] 